\title{
DO UNIVERSAL AO PLURIVERSAL: QUESTÕES E DESAFIOS DO PARADIGMA DECOLONIAL ${ }^{1}$
}

\author{
From Universal to Pluriversal: Issues and Challenges of \\ Decolonial Paradigm
}

Claude BOURGUIGNON ROUGIER
Université Grenoble-Alpes
admin@reseaudecolonial.org

Philippe COLIN

Université de Limoges

philippe.colin@unilim.fr

Tradução de Dalvino VERONESE PASSARIN

Universidade Federal do Paraná dalvino.veronese@gmail.com https://orcid.org/0000-0002-3708-5867

\begin{abstract}
RESUMO: O texto a seguir é uma tradução de «De l'universel au pluriversel. Enjeux et défis du paradigme décolonial», artigo de Claude Bourguignon Rougier e Philippe Colin, publicado na revista Raison Présente ( ${ }^{\circ}$ 199) em 2016. Citando autores como Enrique Dussel, Aníbal Quijano, Edgardo Lander, Walter Mignolo, Santiago Castro-Gómez, Arturo Escobar, Nelson Maldonado Torres, Ramón Grosfoguel e Catherine Walsh, cujas contribuições teóricas têm grande importância, Claude Bourguignon Rougier e Philippe Colin trazem questões e desafios do paradigma decolonial, que se debruça sobre a "geopolítica do poder, do saber e do ser" resultante do processo colonizatório europeu sobre partes do globo. Ressaltam a centralidade epistêmica da colonialidade e sua íntima relação com a modernidade construída sobre uma narrativa eurocêntrica; Rougier e Colin propõem, assim, uma pauta não mais baseada na elaboração de conhecimento a partir de um viés eurocentrista, mas pluriversal, conferindo a devida importância às histórias locais e possibilitando, com isso, reavaliar o lugar de enunciação convencionado pela modernidade. A tradução deste artigo ao português brasileiro visa a tornar acessível a leitura àqueles que demonstrem interesse na abordagem proposta pelos autores, possibilitando, com isso, a diversidade de pontos de vista e o consequente enriquecimento do debate acerca do giro decolonial.
\end{abstract}

\footnotetext{
${ }^{1}$ Publicação original: BOURGUIGNON Claude, COLIN Philippe. De l'universel au pluriversel: enjeux et défis du paradigme décolonial. In: Raison présente, 2016/3 (ํㅜ 199), p. 99-108.
} 
PALAVRAS-CHAVE: decolonial, eurocentrista, modernidade, pluriversal.

\begin{abstract}
The following text is a translation of «De l'universel au pluriversel. Enjeux et défis du paradigme décolonial», written by Claude Bourguignon Rougier and Philippe Colin, published in Raison Présente $\left(n^{\circ} 199\right)$ in 2016. Some authors with very important theoretical contributions are cited, such as Enrique Dussel, Aníbal Quijano, Edgardo Lander, Walter Mignolo, Santiago Castro-Gómez, Arturo Escobar, Nelson Maldonado Torres, Ramón Grosfoguel and Catherine Walsh. It is about issues and challenges regarding the decolonial paradigm, which focuses on the "geopolitics of power, knowledge and being" that resulted from the European colonization process over parts of the globe. Rougier and Colin emphasize the epistemic centrality of coloniality and its intimate relationship with modernity, which was built according to a Eurocentric narrative; therefore, knowledge elaboration should no longer be based on a Eurocentric point of view, but on a pluriversal one, giving due importance to local histories and thus making it possible to reassess the locus of enunciation established by modernity. The translation of this article into Brazilian Portuguese aims to make it accessible to those who show an interest in the subject, thereby enabling the diversity of points of view and the consequent enrichment of the debate about the decolonial turn. KEYWORDS: Decolonial; Eurocentric; Modernity; Pluriversal.
\end{abstract}

A América Latina experiencia, faz duas décadas, uma sequência histórica de intensa criatividade política, social e cultural que a torna, para muitos observadores do "velho mundo", o laboratório das utopias coletivas concretas. A teoria crítica latinoamericana, inteiramente imersa nesse caldeirão de práticas e de ideias, vive também, após duas décadas de um relativo eclipse, um novo sopro, reconfigurando profundamente o conjunto de problemáticas que atravessam o campo das ciências sociais. Segundo o antropólogo colombiano Arturo Escobar (2010, p. 3), essa renovação da teoria crítica segue hoje duas vias principais: a de uma crítica ao modelo neoliberal e outra, mais radical, de uma reanálise da narrativa autorreferencial da modernidade. Os pesquisadores que gravitam em torno do programa Modernidade/Colonialidade se engajaram resolutamente na segunda via há pouco mais de uma década: a partir do conceito-chave de colonialidade, eles procuram elaborar uma crítica ao eurocentrismo e à metanarrativa modernista que estão no centro dos conhecimentos hegemônicos produzidos no Norte global. Eles afirmam, conjuntamente, ao mobilizar noções de pluriversalidade e de diversalidade, 
a absoluta necessidade ética e prática de levar a sério as histórias locais e as epistemes fronteiriças que surgem nas falhas do sistema mundo moderno/colonial.

Essa rede de pesquisadores espalhados em universidades do sul e do norte do continente americano opera em campos disciplinares e horizontes teóricos diversos. A rede se constituiu pouco a pouco, com diálogos, colóquios e publicações coletivas, numa "comunidade de interpretação", dotada de um aparato conceitual específico que lhe permite dialogar para além das divergências metodológicas ou políticas. Dentre os autores com as contribuições teóricas mais importantes, serão citados o filósofo argentino Enrique Dussel, o sociólogo peruano Aníbal Quijano, o sociólogo venezuelano Edgardo Lander, o semioticista argentino Walter Mignolo, o filósofo colombiano Santiago Castro-Gómez, o antropólogo colombiano Arturo Escobar, o filósofo porto-riquenho Nelson Maldonado Torres, o sociólogo porto-riquenho Ramón Grosfoguel e a intelectual da cultura norteamericana Catherine Walsh. Se, desde o fim da década, as divergências teóricas desses autores parecem se acentuar e se seus trabalhos coletivos parecem se tornar cada vez mais raros, o "giro decolonial", a cuja teorização eles contribuíram, experimenta um formidável prestígio: é hoje toda uma rede acadêmica, implantada em diversos países da América do Sul, que se apropriou da temática da colonialidade, buscando, assim, o desenvolvimento desse programa teórico ${ }^{2}$.

Se a teoria decolonial se inscreve inegavelmente na onda de choque provocada pelo desenvolvimento epistemológico e institucional dos postcolonial e dos subaltern studies no mundo, ela não constitui, no entanto, uma simples aclimatação regional. O espaço de reflexão aberto pelo paradigma decolonial coincide, de fato, apenas muito parcialmente com o pós-colonialismo. Seu principal objeto de estudo não é o colonialismo e seus efeitos duráveis sobre as estruturas simbólicas das sociedades póscoloniais, mas a geopolítica do poder, do saber e do ser que emerge com a colonização europeia da América e se consolida com a extensão do sistema mundial capitalista no conjunto do globo. A perspectiva decolonial propõe, na realidade, uma inversão da ordem causal "intramoderna" que rege a historiografia pós-colonial: a colonialidade, longe de ser apenas um resíduo ou uma sequela de uma violência original - o colonialismo - de que a modernidade teria progressivamente se afastado, constitui na realidade sua matriz epistêmica. Em outras palavras, os imaginários pós-coloniais que a teoria "pós" tende a apreender como persistências históricas de uma ordem global caduca, constituem,

\footnotetext{
${ }^{2}$ Citemos, a título de exemplo, o Doutorado em Estudos Culturais da Universidade Simón Bolívar de Quito, o Instituto de Estudos Sociais Contemporâneos (IESCO) da Universidade Central de Bogotá, ou ainda o Instituto de Estudos Sociais e Culturais PENSAR da Pontificia Universidad Javeriana em Bogotá.
}

Revista X, v. 16, n. 1, p. 148-158, 2021. 
para a perspectiva decolonial, as manifestações sintomáticas de uma estrutura cognitiva profunda que está ainda em ação na configuração das relações norte/sul.

\section{DESCONSTRUIR A NARRATIVA EUROCÊNTRICA DA MODERNIDADE}

É a Enrique Dussel que se atribui a percepção da necessidade de combater o que ele chama, a partir do início dos anos 90, numa obra publicada na ocasião da celebração dos 500 anos da "descoberta" da América, de "mito intraeuropeu da Modernidade" (DUSSEL, 1993). O filósofo argentino considera, de fato, que a Modernidade - o conjunto de modos de organização da vida social que conhecemos hoje - não foi secretada por processos internos ao desenvolvimento da Europa, mas que ela literalmente surgiu do encontro entre a Europa e a América, precisamente em 1492.

A Europa ocidental não era o "centro", nem sua história nunca fora o
centro da história. Será preciso esperarpor 1492 para que sua centralidade
empírica constitua as outras civilizações como sua "periferia". Este
fato da "saída" da Europa Ocidental dos estreitos limites dentro dos
quais o mundo muçulmano a prendera constitui, em nossa opinião, o
nascimento da Modernidade (DUSSEL, 1993, p. 113).

Encontram-se nessa proposição elementos da teoria macrossociológica do sistema mundial elaborada por Immanuel Wallerstein. O sociólogo estadunidense contribui, com efeito, desde o início dos anos 70, para "desprovincializar" os processos que levam à modernidade, mostrando que sua história não é coextensiva à da Europa, mas que ela surgiu da interação assimétrica entre a Europa e o continente americano (WALLERSTEIN, 1976). A leitura que Dussel faz dessa teoria se afasta, todavia, da análise materialista de Wallerstein. Para o filósofo argentino, essa primeira modernidade não foi só o lugar de uma gigantesca acumulação primitiva predatória, mas também o espaço do surgimento de uma nova geocultura, que detém uma forma-sujeito específica:

[A modernidade] nasceu quando a Europa pôde se confrontar com o seu "Outro" e controlá-lo, vencê-lo, violentá-lo: quando pôde se definir com um "ego" descobridor, conquistador, colonizador da Alteridade constitutiva da própria Modernidade (DUSSEL, 1993, p. 8).

O ego conquiro europeu da primeira modernidade constituiria desde então o imperativo prévio ao sujeito autocentrado - o ego cogito - da segunda modernidade. Simetricamente, o surgimento dessa forma-sujeito "colonizadora" inclinada ao "ceticismo 
misantrópico" (MALDONADO TORRES, 2007, p. 134) implicou necessariamente o surgimento de uma subjetividade colonizada, cuja primeira característica foi a de ser negada em sua alteridade, ou seja, pura e simplesmente suprimida em seu próprio ser: "O índio não foi descoberto como o Outro mas como 'o mesmo' já conhecido (o asiático) e somente reconhecido (negado então como Outro: 'encoberto')" (MALDONADO TORRES, 2007, p. 32). As populações autóctones não foram somente desapropriadas de suas terras, como também de suas identidades culturais: por uma operação discursiva de uma extrema violência, astecas, incas, maias, aimarás, araucanos foram homogeneizados, essencializados e depois designados a um referente identitário fantasioso, que viria a se tornar a marca durável de sua inferioridade social.

A releitura da teoria do sistema mundial por Dussel acarreta uma série de consequências teóricas que serão fundamentais na reflexão do grupo Modernidade/ Colonialidade. Ao situar as origens da modernidade não no século XVIII, mas no curso da sequência histórica aberta pela conquista da América após 1492, Dussel afirma, com efeito, simultaneamente:

- a dimensão imediatamente global da modernidade;

- a indissociabilidade do fato colonial e da modernidade;

- a patologização e inferiorização do Outro como processo constitutivo da modernidade;

- o surgimento de um sistema de saber/poder eurocentrado que repousa sobre a confusão entre "a universalidade abstrata com a mundialidade concreta hegemonizada pela Europa como "centro"' (DUSSEL, 2005, p. 30).

Para Dussel, a modernidade não é somente um processo sócio-histórico, mas antes de tudo a narrativa autointerpretativa pela qual a Europa apreende sua relação com o Outro. Essa grande metanarrativa, da passagem do reino da loucura ao da razão, apresenta-se, contudo, uma vez operada essa inversão de perspectiva, como um discurso apologético visando a justificar o que, do outro lado da ruptura colonial, é vivido não mais como a superação histórica de formas sociais arcaicas, mas como uma "práxis irracional da violência" associada a um gigantesco projeto global de despojos e de apropriações.

\section{A COLONIALIDADE DO PODER}

Deve-se o conceito de colonialidade do poder ao sociólogo peruano Aníbal Quijano, que o introduziu pela primeira vez em 2009, em seu artigo "A colonialidade do poder e a classificação social". Ele a definiu da seguinte maneira: 
A colonialidade é um dos elementos constitutivos e específicos do padrão mundial do poder capitalista. Sustenta-se na imposição de uma classificação racial/étnica da população do mundo como pedra angular do referido padrão de poder e opera em cada um dos planos, meios e dimensões, materiais e subjectivos, da existência social quotidiana e da escala societal. Origina-se e mundializa-se a partir da América (QUIJANO, 2009, p. 73).

Assim, o capitalismo colonial/moderno, enquanto regime de poder historicamente determinado, funda sua operacionalidade sobre uma matriz epistêmica dada: a colonialidade. Seria possível defini-la como um regime de representação hierarquizado e compartimentado do mundo social. Segundo Quijano, é a convergência e a associação de dois processos históricos independentes, no espaço-tempo americano, que vai permitir o estabelecimento desse regime de poder específico: de um lado, a naturalização da relação de dominação originada da conquista e da colonização ibérica por meio da noção classificatória de raça; de outro, "a articulação de todas as formas históricas de controle do trabalho, de seus recursos e de seus produtos, em torno do capital e do mercado mundial" (QUIJANO, 2005, p. 117). Assim, as diferentes formas de trabalho articuladas nos regimes coloniais extrativistas foram distribuídas de acordo com uma rígida hierarquia racial, a qual foi fundada sobre a atribuição de uma valência diferencial aos fenótipos corporais: desde o início da conquista do continente americano, o trabalho coercitivo foi designado àqueles que haviam sido anteriormente categorizados como "bárbaros"; em seguida, bastante rapidamente, às populações arrancadas do continente africano para compensar a sobremortalidade dos autóctones.

Essa associação, embora historicamente secundária, teve consequências ao mesmo tempo duráveis e de um alcance global: ela não somente permitiu que a raça se impusesse no longo prazo como o critério fundamental de classificação social da população mundial, como também levou à universalização de uma distribuição racializada das relações de produção. A articulação de todas as formas históricas de controle do trabalho no seio do sistema mundial capitalista colonial/moderno se realizou efetivamente na base de uma grande divisão estruturante: as formas de trabalho não assalariadas aos não-brancos da não-Europa, o regime assalariado à raça dos “senhores” europeus (QUIJANO, 2005).

Se a racialização das relações de produção constitui, para Quijano, a pedra angular da colonialidade do poder, seu domínio não incide somente sobre a esfera do trabalho, ele penetra no conjunto dos domínios da existência social, onde se constituem os jogos do poder. A operação de racialização age, efetivamente, simultânea e inseparavelmente sobre o trabalho, a natureza, o sexo, a subjetividade (ou seja, os imaginários e os conhecimentos 
produzidos) e, por fim, sobre a autoridade (QUIJANO, 2009). Essa dimensão totalizante da colonialidade é, aliás, regularmente destacada por Ramón Grosfoguel (2009, p. 13), para quem o "capitalismo historicamente existente" não é um sistema econômico, mas um "sistema hegemônico" fundado sobre uma rede de "hierarquias globais" não congruentes. Tal concepção, compreende-se, torna caduca toda análise do sistema hegemônico global em termos de infraestrutura e de superestrutura.

O sistema mundial é desde então muito mais do que um sistema econômico: é uma civilização, dito de outro de modo, um sistema civilizador fundado sobre uma concepção colonial do poder e composto por uma rede de relações de poder múltiplas e heterogêneas, inextricavelmente ligadas entre si, que privilegiam as populações ocidentais em relação às populações não ocidentais (GROSFOGUEL; CAIRO, 2010, p. 13).

Seria então possível dizer, estendendo o raciocínio, que a colonialidade, em última instância, não é uma forma superestrutural dependente de determinantes econômicos, mas um eixo estruturante que articula uma multiplicidade de relações de dominação.

\section{POR UMA NOVA GEOPOLÍTICA DO SABER}

Em sua obra clássica, The Darker Side of the Renaissance, Walter Mignolo formula a hipótese de que a dissociação estabelecida pelos geógrafos europeus no século XVI entre o ponto de observação étnico e o ponto de observação geométrico constituiria uma das chaves que permitem compreender a implementação, ao longo do mesmo período, das abstrações normativas que fundam o sistema de saber/poder moderno. Segundo Mignolo, até o século XVI, o centro "étnico" e o centro "geométrico" são apenas um. Assim, as representações espaciais medievais europeias funcionam no modo axis mundi: elas são estruturadas ao redor de um local sagrado - Roma, Jerusalém - que é ao mesmo tempo o centro étnico e geométrico da representação. Ora, de acordo com Mignolo, o movimento de expansão global da Europa, e particularmente a conquista da América, desarranjam por longo tempo o regime de representação ocidental do espaço: a vontade de acumular informação e de controlar os espaços colonizados conduz os cartógrafos que obram para as coroas ibéricas a integrar a perspectiva geométrica no seio de suas representações. Essa passagem do axis mundi ao mapa mundi, em termos de representação do poder, é capital: a racionalização geométrica do espaço, ao realocar o centro étnico ou religioso - que se torna, então, móvel - cria a ilusão de um olhar desapegado, objetivo, exterior à representação, superando o que aparece como puro objeto transparente (MIGNOLO, 1995, p. 226). Santiago Castro-Gómez (2005, p. 25) conceitualizou essa fantasia da consciência absoluta, descolada de todo lugar de enunciação, ao forjar a noção "de hybris 
do ponto zero". A hybris do ponto zero seria, então, o modelo hegemônico de produção de conhecimento que, de acordo com o modelo da épochè cartesiana, põe o mundo em suspenso e se institui como começo absoluto, arrogando, a propósito, um poder exorbitante sobre o que ele objetiva. $\mathrm{O}$ eurocentrismo moderno/colonial aparece assim como uma forma específica de etnocentrismo: seria possível defini-lo como um regime da verdade fundado sobre uma confusão sistemática entre a universalidade abstrata e a hegemonia mundial concreta decorrente da posição central do Ocidente no seio do sistema mundial.

Colocam-se duas questões essenciais: é possível construir um lugar de enunciação que fuja, mesmo que parcialmente, do domínio do dizível circunscrito pelo regime da verdade moderno/colonial? Existe uma posição de exterioridade em condições de articular uma crítica da modernidade que não seja intraeuropeia? Para Walter Mignolo, a colonialidade, precisamente por ser aquilo que a modernidade deve excluir e eliminar para se instaurar como tal, pode também se tornar o lugar de enunciação - o stand point - que torna visível o ponto cego da modernidade. O local heterotópico da "diferença colonial" não é mais, desde então, somente o espaço da designação racial e da relegação social, aparece também como um espaço epistêmico e político privilegiado a partir do qual se torna possível observar a dupla face do sistema mundial moderno/colonial.

Walter Mignolo, ao se inspirar estritamente nas noções de "dupla consciência" de Du Bois ou de third space de Homi Bhabba, forjou a categoria central do "pensamento fronteiriço" para descrever as práticas epistêmicas dos intelectuais do sul que ocupam um "lugar de enunciação dicotômico [...] situado nas fronteiras internas ou externas do sistema-mundo colonial" (MIGNOLO, 2000, p. 85). Ao articular suas próprias tradições epistêmicas ao "cânone" moderno/colonial majoritário, esses intelectuais minoritários engendram um novo lugar de enunciação, um lugar que se situa na linha divisória traçada pela diferença colonial. Simetricamente, do outro lado da fronteira colonial, os intelectuais do norte que se engajam em práticas do devir minoritário, que dialogam com as singularidades mais opostas ao regime majoritário, também eles engendram um pensamento fronteiriço, um locus que visa a fissurar o sonho u-tópico da modernidade. A atualização do pensamento fronteiriço, na sua dupla vertente, permite politizar o que a modernidade/colonialidade constituiu como diferença ontológica.

No pensamento filosófico de Enrique Dussel, a possibilidade de um lugar epistêmico "outro", que não seja o não-lugar tendencialmente produzido pela modernidade, é igualmente central. Ela lhe permite, com efeito, conceber a superação da modernidade sob a forma específica de uma transmodernidade. O filósofo argentino define a transmodernidade como o projeto utópico que visaria a atravessar a modernidade/ 
colonialidade, não ao negá-la, mas ao apreendê-la desde a sua exterioridade relativa, desde o stand point da alteridade:

O projeto transmoderno é uma correalização do impossível para a Modernidade; ou seja, é correalização de solidariedade, que chamamos de analéptica [...]; não por pura negação, mas por incorporação partindo da Alteridade (DUSSEL, 2005, p. 31, grifo no original).

Uma vez que, segundo Dussel, a pós-modernidade nunca é somente a superação da modernidade no contexto do regime da verdade moderno/colonial - dito de outro modo, uma forma de hipermodernidade - a transmodernidade se apresenta quanto a ela como um projeto de interconexão e de interfecundação entre tradições e genealogias epistêmicas diferentes; um projeto que visaria a "um além de toda possibilidade interna à única modernidade". Se o projeto transmodernidade se apresenta abertamente como uma antecipação utópica, ele encontra no real, contudo, condições de realização efetiva. Enrique Dussel afirma assim que, a despeito de suas pretensões totalizantes, o "poder de subsunção" da Modernidade sempre foi parcial: não somente jamais aboliu integralmente a alteridade, como também produziu, nas periferias do sistema mundial, um grande número de imaginários híbridos (DUSSEL, 2004, p. 205). Essa "exterioridade massiva" gera muitas práticas e histórias locais que, embora em luta contra a modernidade, são-lhe indissociáveis. São essas histórias locais que desenham, de agora em diante, a possibilidade de uma globalização que não seja uma universalização da episteme eurocentrista, mas um processo de pluriversalização do mundo (MIGNOLO, 2010, p. 16).

\section{CONCLUSÃO}

Ao fazer dialogarem os saberes e as práticas militantes das comunidades afrocolombianas e as teorias críticas do norte global, Arturo Escobar (2014) elabora atualmente uma reflexão original sobre a matriz ontológica da episteme moderno/colonial e sobre as modalidades concretas de sua superação transmoderna. $\mathrm{O}$ antropólogo colombiano aponta com isso a necessidade de realizar, após o trabalho incontornável de destruição da ontologia dualista que funda a experiência moderno/colonial do mundo, uma "política da ontologia" que visaria a explorar as potencialidades "emancipatórias" das concepções do mundo operantes na base de pressupostos epistemológicos, epistêmicos e ontológicos diferentes (ESCOBAR, 2013, p. 15-42). Construir tal espaço dialógico não significa que seja necessário nos desfazermos de nosso próprio ponto de vista e adotar o ponto de vista do Outro: como afirma Mario Blaser (2010, p. 23), tal diálogo transfronteiriço 
"aspira, em última instância, a produzir um stand point que funcionaria como um lugar de mediação capaz de articular simetricamente os mundos/realidades que a diferença colonial articula hierarquicamente".

O desafio é grande: levar a sério os conflitos epistêmicos que se multiplicam na América Latina e em outras partes do globo supõe, com efeito, que estejamos dispostos, após décadas de uma longa e necessária luta epistemológica contra as essencializações, a reavaliar o potencial emancipatório das "histórias locais"; isso implica também, e sobretudo, que sejamos capazes de abandonar o confortável locus moderno de enunciação que ocupamos e de aceitar que o pluriverso possa alterar a maneira como interagimos com o mundo.

\section{REFERÊNCIAS}

BLASER, Mario. Storytelling Globalization from the Chaco and Beyond. Duke University Press: Durham, 2010.

CASTRO-GÓMEZ, Santiago. La Hybris del Punto Cero. Ciencia, Raza e Ilustración en la Nueva Granada (1750-1816). Editorial Pontificia Universidad Javeriana: Bogotá, 2005.

DUSSEL, Enrique. 1492. O Encobrimento do Outro: A Origem do Mito da Modernidade. Tradução de Jaime A. Clasen. Petrópolis: Vozes, 1993. Disponível em: http://www.mel. unir.br/uploads/56565656/arquivos/1492_O_encobremento_do_outro_de_ENRIQUE_ DUSSEL_441400838.pdf. Acesso em 06/05/2020.

DUSSEL, Enrique. Europa, Modernidade e Eurocentrismo. CLACSO: Buenos Aires, 2005. Disponível em: http://biblioteca.clacso.edu.ar/gsdl/collect/clacso/index/assoc/ D1200.dir/5_Dussel.pdf. Acesso em: 25/05/2020.

DUSSEL, Enrique. Sistema mundo y Transmodernidad. In: DUBE, Saurabh; BANERJEE, Ishita; MIGNOLO, Walter. (eds.). Modernidades Coloniales. México DF: Ediciones El Colegio de México, 2004.

ESCOBAR, Arturo. En el Trasfondo de Nuestra Cultura: la Tradición Racionalista y el Problema del Dualismo Ontológico. Tabula Rasa, n. 18, jan./jun. 2013.

ESCOBAR, Arturto. Latin America at Crossroads. Cultural Studies, v. 24, n. 1, 2010.

ESCOBAR, Arturo. Sentipensar con la Tierra. Nuevas Lecturas sobre Desarollo, Territorio y Diferencia. Medellín: Ediciones Unaula, 2014. 
GROSFOGUEL, Ramón. Izquierdas e izquierdas otras: entre el proyecto de la izquierda eurocêntrica y el proyecto transmoderno de las nuevas izquierdas descoloniales. Tábula Rasa, n. 11, jul./dez. 2009.

GROSFOGUEL, Ramón; CAIRO, Heriberto. Descolonizar los sueños de la razón para dejar de producir monstruos. In: CAIRO, Heriberto; GROSFOGUEL, Ramón (eds.). Descolonizar la modernidad, descolonizar Europa. Un diálogo Europa - América Latina. Madrid: IEPALA, 2010.

MALDONADO TORRES, Javier. Sobre la colonialidad del ser; contribuciones al desarollo de un concepto. In: CASTRO-GÓMEZ, Santiago; GROSFOGUEL, Ramón (eds.). El giro decolonial, Reflexiones para una diversidad epistémica más allá del capitalismo global. Bogotá: Siglo del Hombre Editores, 2007.

MIGNOLO, Walter. Desobediencia Epistémica: Retórica de la Modernidad, Lógica de la Colonialidad y Gramática de la Descolonialidad. Buenos Aires: Ediciones del Signo, 2010 .

MIGNOLO, Walter. The Darker Side of Renaissance: Literacy, Territoriality \& Colonization. Ann Arbor: University of Michigan Press, 1995.

MIGNOLO, Walter. Local Histories / Global Designs. Coloniality, Subaltern Knowledges and Border Thinking. Princeton: Princeton University Press, 2000.

QUIJANO, Aníbal. Colonialidade do Poder e Classificação Social. In: SANTOS, Boaventura Sousa; MENESES, Maria Paula (org.). Epistemologias do Sul. Coimbra: Edições Almedina, 2009. Disponível em: http://www.mel.unir.br/uploads/56565656/ noticias/quijano-anibal $\% 20$ colonialidade $\% 20 \mathrm{do} \% 20$ poder $\% 20 \mathrm{e} \% 20$ classificacao $\% 20$ social.pdf. Acesso em 16/05/2020.

QUIJANO, Aníbal. Colonialidade do poder, eurocentrismo e América Latina. Buenos Aires: CLACSO, 2005. Disponível em: http://biblioteca.clacso.edu.ar/clacso/sursur/20100624103322/12_Quijano.pdf. Acesso em 17/05/2020.

WALLERSTEIN, Immanuel. The Modern World-System: Capitalist Agriculture and the Origins of the European World-Economy in the Sixteenth Century. New York: Academic Press, 1976. 